\title{
Comparativo entre diferentes solubilizadores usados na produção de filmes de quitosana
}

\author{
J. A. SANTOS ${ }^{1}$, D. R. LIMA ${ }^{1}$, A. O. CARDOSO ${ }^{1}$, A. B. dos REIS ${ }^{1 *}$ \\ ${ }^{1}$ Universidade Federal dos Vales do Jequitinhonha e Mucuri, Instituto de Ciência e \\ Tecnologia
}

Email: jacqueline_amarinho@yahoo.com.br; dirlene_lima@yahoo.com.br anamaria.cardoso@ict.ufvjm.edu.br; * *arlete.reis@ict.ufvjm.edu.br

\begin{abstract}
RESUMO - A quitosana é um polissacarídeo que ocorre naturalmente na natureza, sendo um composto biodegradável e biocompatível que pode ser utilizado entre outras coisas para confecção de filmes transparentes com uma boa resistência. A capacidade de absorção desses filmes pode ser medido pela Lei de Fick, que fornece a capacidade de difusão de um composto em um meio. Esse trabalho teve como objetivo a produção de filmes de quitosana a partir da quitosana POLYMAR com grau de desacetilação de $88 \%$, em placas de retangulares, onde a mesma reagiu com o ácido acético e com o ácido succínico. Após prontas, as membranas foram mantidas em um ambiente com umidade controlada dentro de um dessecador contendo uma solução de $\mathrm{NaCl}$, e suas espessuras foram medidas em regulares intervalos de tempo por 98 horas. A partir dos dados obtidos gráficos foram plotados, e notaram-se diferentes comportamentos das linhas plotadas em função dos reagentes utilizados, isso mostrou que as membranas apresentam propriedades distintas devido à adição em uma delas do ácido succínico, o que mudaria as possíveis aplicações desses filmes. O presente trabalho teve como objetivo a produção de filmes de quitosana tendo como solubilizadores o ácido acético e o ácido succínico para avaliação da sua difusividade.
\end{abstract}

\section{INTRODUÇÃO}

A quitosana é um amino polissacarídeo que ocorre naturalmente na natureza em pequenas quantidades nas paredes celulares e esporos de alguns fungos (Mucor e Zygomicetes), ou pode ser obtida pela hidrólise alcalina da quitina, principal componente dos exoesqueletos dos artrópodes, sendo um composto biodegradável e biocompatível. Sua estrutura é formada pela repetição de unidades beta (1-4) 2-amino2-deoxi-D-glucose (ou D-glucosamina) e apresenta uma cadeia polimérica quimicamente similar à da celulose. A quitosana é solúvel em ácidos inorgânicos e diluída em ácidos orgânicos com pH menor que 6, sendo insolúvel em água, ácidos concentrados, acetonas, e álcool DALLAN (2005).

O que faz da quitosana um material de interesse é seu amplo espectro antimicrobiano que, associado à biocompatibilidade e à biodegradabilidade, a torna 
particularmente interessante para aplicações na agricultura, medicina, meio ambiente e alimentos, dentre outras aplicações ASSIS (2010). Embora apresente múltiplas propriedades, seu uso como material de engenharia é limitado por apresentar alta afinidade por água ASSIS (2010).

$\mathrm{Na}$ presença de soluções aquosas diluídas de ácidos, a quitosana comporta-se como polieletrólito, causando o surgimento de interações repulsivas eletrostáticas entre os grupos amino ionizados ao longo da cadeia polimérica WANG, et al. (1991). Assim, para caracterizar o comportamento desse polímero em solução, é importante selecionar o sistema de solvente mais apropriado RINAUDO et al. (1993) e observar o que esses efeitos podem causar nas propriedades desses filmes produzidos.

Membranas de quitosana são comumente preparadas pela evaporação em placas de vidro do ácido formando películas finas e transparentes com resistência considerável LIMA (2006). O coeficiente de difusão indica o grau de absorção dessa membrana pode ser medido através do calculo da equação da Lei de Fick.

A Segunda Lei de Fick é bastante utilizada quando se tem o interesse de saber a difusão de um fluido, em função da sua concentração e da difusividade do material, essa lei é especialmente abordada quando o fluido em questão é a água COSTA (2001). A segunda Lei de Fick é dada pela equação 1 e assume características especiais de acordo com as condições de contorno do regime de difusão no sistema analisado.

$$
\frac{\partial \mathrm{C}}{\partial t}=D \frac{\partial^{2} c}{\partial x^{2}}
$$

Onde,

$\mathrm{D} \rightarrow$ coeficiente de difusão expresso $\mathrm{m}^{2} / \mathrm{s}$. Quando o sinal é negativo indica que a direção de difusão é contrária ao gradiente.

$\partial^{2} \mathrm{C} / \partial \mathrm{x}^{2} \rightarrow$ gradiente de concentração no meio.

$\partial \mathrm{C} / \partial \mathrm{t} \rightarrow$ gradiente de concentração no tempo.

\section{OBJETIVO}

Preparar filmes a base de quitosana com diferentes solubilizadores analisar o coeficiente de difusão e a permeabilidade ao vapor d'água. 


\section{METODOLOGIA}

Para o preparo das amostras dos filmes de quitosana solubilizados com ácido foram utilizadas as seguintes proporções do ácido acético e do ácido succínico:

Tabela 1- Solubilizadores Utilizados

\begin{tabular}{cccc}
\hline Nomenclatura & Quitosana (g) & $\begin{array}{c}\text { Ácido } \\
\text { Acético (mL) }\end{array}$ & $\begin{array}{c}\text { Ácido } \\
\text { Succínico (g) }\end{array}$ \\
\hline Filme Q4\% Ac & 4 & 1,12 &
\end{tabular}

Filme Q4\% Ac $\quad 4 \quad 1,12 \quad-$

Filme Q4\% As $\quad 4 \quad 1,12 \quad 2$

NOTA: Q4\%Ac= Filmes produzidos a partir de quitosana solubilizados pelo ácido acético.

Q4\%As= Filmes produzidos a partir de quitosana com ácido acético e ácido succínico como solubilizadores.

\subsection{FILMES DE QUITOSANA SOLUBILIZADA COM ÁCIDO ÁCETICO}

Os filmes foram preparados a partir de quitosana da marca POLYMAR com grau de desacetilação de $88 \%$ dissolvida em solução aquosa de ácido acético $1,12 \%$ em um béquer. Preparou-se duas soluções na forma exposta de $100 \mathrm{~mL}$. Essas soluções foram levada a uma agitação de $40 \mathrm{rpm}$ por um período de uma hora e posteriormente à aquecimento durante 60 minutos para completar a diluição da quitosana na solução. A mistura viscosa formada foi disposta em seis placas retangulares planas de acrílico de $13,5 \mathrm{~cm} \times 3 \mathrm{~cm}$ contendo $25 \mathrm{~mL}$ da solução cada uma. Tais placas foram levadas para uma estufa a $35^{\circ} \mathrm{C}$, onde permaneceram por 48 horas ou até o período de completa secagem dos filmes.

\subsection{FILMES DE QUITOSANA SOLUBILIZADA COM ÁCIDO ACÉTICO E ÁCIDO SUCCÍNICO}

As membranas Q4\%As foram preparadas a partir de quitosana da marca POLYMAR com grau de desacetilação de $88 \%$ assim como as citadas anteriormente, dissolvida em solução aquosa de ácido acético 1,12\% em um béquer. Foram preparadas duas soluções na forma exposta de $100 \mathrm{~mL}$. Essas soluções foram levadas a uma agitação de $40 \mathrm{rpm}$ por um período de uma hora, posteriormente aqueceu-se as mesma durante 60 minutos para completar a diluição da quitosana na solução. A mistura viscosa formada foi disposta em seis placas retangulares planas de acrílico de $13,5 \mathrm{~cm} \mathrm{x}$ $3 \mathrm{~cm}$ contendo $25 \mathrm{~mL}$ da solução cada uma. Tais placas foram encaminhadas para uma estufa a $35^{\circ} \mathrm{C}$, onde permaneceram por 48 horas ou até o período de completa secagem dos filmes. 


\subsection{ANÁLISE DO COEFICIENTE DE DIFUSÃO}

Para realizar o estudo do coeficiente de difusividade dos filmes Q4\%Ac e Q4\%As foi preparado um dessecador de vidro contendo sílica completamente seca depositada ao fundo, para obter um ambiente com umidade zero. Essa sílica foi mantida durante 48 horas no dessecador. Ao fim desse período os filmes foram devidamente pesados em uma balança de precisão e mediu-se a espessura das mesmas utilizando um paquímetro.

A sílica foi retirada do dessecador, e no mesmo foram colocados pequenos frascos contendo soluções saturadas de $\mathrm{NaCl}$. As membranas então foram dispostas no dessecador.

Realizaram-se por um período de 98 horas a pesagem diária das membranas a fim de analisar a absorção de umidade. Ao fim desse período a espessura e a massa destas foram novamente medida.

\subsection{PERMEABILIDADE A VAPOR D'AGUA}

De acordo com a ASTM E96-95 permeabilidade é a taxa de transmissão de vapor de água por unidade de área através do filme, de espessura conhecida, induzida por um gradiente de pressão entre duas superfícies específicas, de umidade relativa e temperatura especificada ASTM (1990). equação:

A permeabilidade ao vapor d'água (PVA) foi determinada nos filmes através da

$$
\text { PVA }=\frac{\Delta \mathrm{m}(\mathrm{g}) * \text { Espessura }_{\text {média }}(\mathrm{mm})}{\text { Área do filme }\left(\mathrm{m}^{2}\right)^{*} \Delta \mathrm{T}^{*} \Delta \mathrm{P}(\mathrm{KPa})}
$$

\section{RESULTADOS E DISCUSSÃO}

Pode se observar nas tabelas 2 e 3 os resultados físicos dos procedimentos descritos no item 3 das análises realizadas com os filmes Q4\%Ac e Q4\%As respectivamente. 
Tabela 2 - Aspectos físicos dos filmes Q4\%Ac

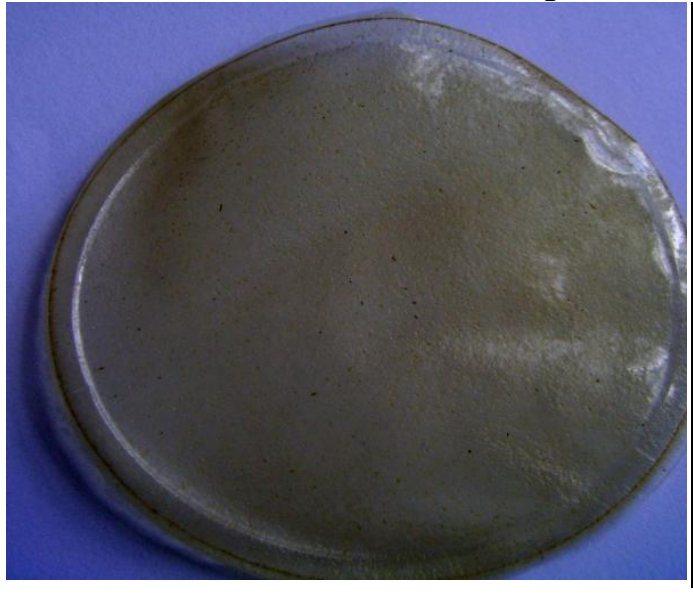

Filme Q4\% Ac

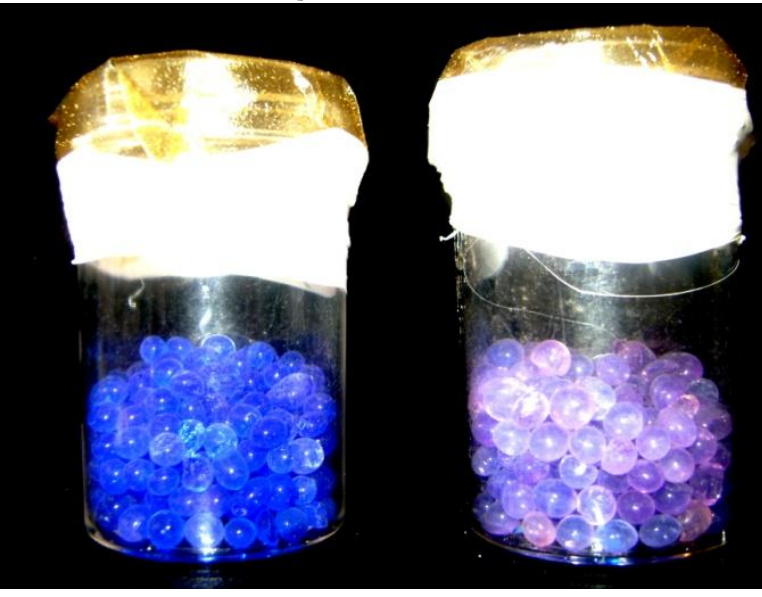

Antes e Depois (PVA)

Foi observada a mudança de cor da sílica o que indica que houve absorção de umidade pelos filmes Q4\%Ac.

Tabela 3 Aspectos físicos dos filmes Q4\%As

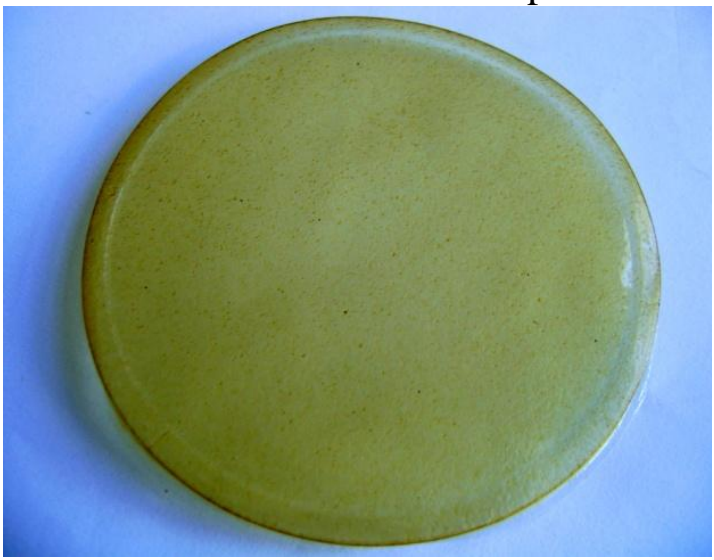

Filme Q4\%As

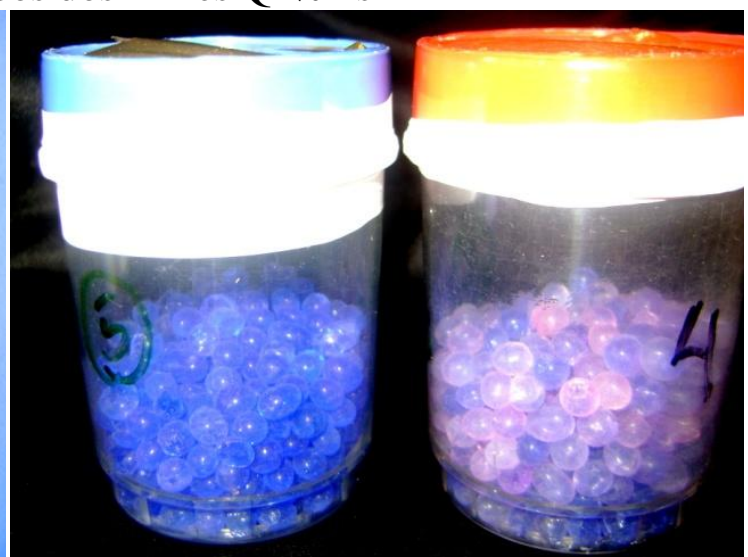

Antes e Depois (PVA)

Os filmes Q4\%As apresentaram ao fim do procedimento uma sílica em um tom de roxo mais forte, o que indica que a absorção de umidade do ambiente foi maior quando comparado aos filmes Q4\%Ac.

No gráfico 1 encontram-se respectivamente os valores médios das massas obtidas durante o período de pesagem dos filmes Q4\%Ac Q4\%As por hora. Pode-se observar que as membranas a base de ácido succínico apresentaram um comportamento mais estável, atingindo o equilíbrio em menor tempo. 
Gráfico 1- Média ganho de massa

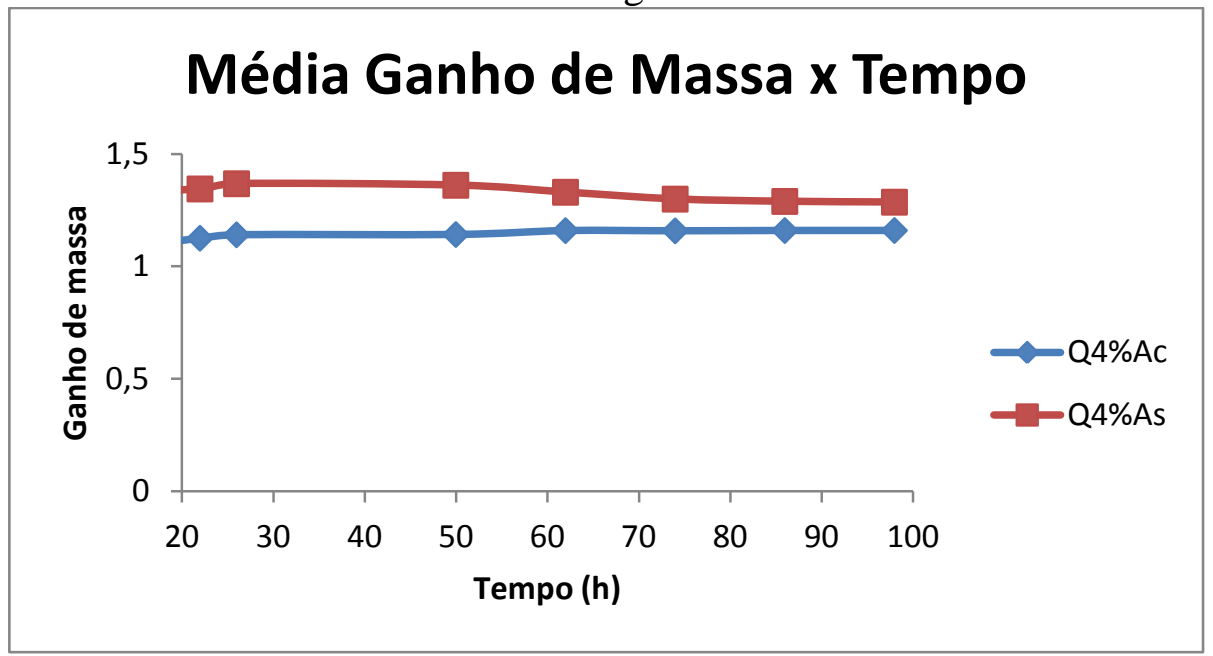

Na realização dos testes de PVA foram obtidos os seguintes valores:

Tabela 4- PVA

\begin{tabular}{ccccccc}
\hline Filme & $\Delta \mathbf{m}(\mathbf{g})$ & $\begin{array}{c}\text { Espessura } \\
(\mathbf{m m})\end{array}$ & $\begin{array}{c}\text { Área } \\
\left(\mathbf{m}^{2}\right)\end{array}$ & $\begin{array}{c}\text { Tempo } \\
(\mathbf{h})\end{array}$ & $\Delta \mathbf{P}(\mathbf{K P a})$ & $\begin{array}{c}\mathbf{P V A}(\mathbf{g} \\
\left.\mathbf{a} \mathbf{g u a} / \mathbf{m}^{2} / \mathbf{d i a}\right)\end{array}$ \\
\hline $\mathbf{Q 4 \% A c}$ & 35,66415 & 0,09 & 0,00159 & 120 & 2,3 & $7,3142^{\mathrm{a}}$ \\
$\mathbf{Q 4 \% A s}$ & 33,633885 & 0,108 & 0,00159 & 120 & 2,3 & $8,2774^{\mathrm{b}}$ \\
\hline
\end{tabular}

NOTA: letras diferentes (a-b) na mesma coluna representam diferença significativa $(p>0,05)$ entre as médias obtidas pelo teste de Tukey.

Resultados referentes a 5 determinações.

Os filmes produzidos a partir do ácido acético apresentaram uma média de coeficiente de difusão de $6,97 \times 10^{-13} \mathrm{~m}^{2} / \mathrm{s}$, enquanto os filmes com o ácido acético e ácido succínico obtiveram uma média de coeficiente de difusão de $1,44 \times 10^{-13} \mathrm{~m}^{2} / \mathrm{s}$. O que comprova que os $\mathrm{Q} 4 \% \mathrm{As}$ possuem maior afinidade coma água, assim maior absorção.

Tabela 5- Coeficiente de difusão das membranas produzidas

Q4\% Ac Q4\%As

\begin{tabular}{cccc}
\hline Amostra & $\begin{array}{c}\text { Coeficiente de difusividade } \\
\left(\mathbf{m}^{2} / \mathbf{s}\right)\end{array}$ & $\begin{array}{c}\text { Amostra } \\
\text { Q1 }\end{array}$ & $\begin{array}{c}\text { Coeficiente de difusividade } \\
\left(\mathbf{m}^{2} / \mathbf{s}\right)\end{array}$ \\
\hline $\mathbf{Q 2}$ & $1,03 \times 10^{-13}$ & $\mathbf{Q 1}$ & $8,78 \times 10^{-14}$ \\
$\mathbf{Q 3}$ & $4,45 \times 10^{-14}$ & $\mathbf{Q 2}$ & $2,54 \times 10^{-14}$ \\
$\mathbf{Q 4}$ & $5,22 \times 10^{-14}$ & $\mathbf{Q 3}$ & $8,31 \times 10^{-14}$ \\
$\mathbf{Q 5}$ & $5,08 \times 10^{-13}$ & $\mathbf{Q 4}$ & $6,36 \times 10^{-13}$ \\
$\mathbf{Q 6}$ & $1,79 \times 10^{-12}$ & $\mathbf{Q 5}$ & $1,04 \times 10^{-14}$ \\
\hline
\end{tabular}


Os valores experimentais indicam que geralmente membranas Q4\%As possuem uma maior capacidade de absorver a umidade do meio. Isso se dá pela afinidade dos polímeros com água, no caso da quitosana é devido ao grupo amino e hidroxila. No caso do ácido succínico é devido aos dois grupos de ácido carboxílicos presentes conforme a figura 1 enquanto que na estrutura do ácido acético existe somente um grupo carboxílico como exposto na tabela 5.

Tabela 6 - Estruturas químicas dos ácidos<smiles>O=C(O)CCC(=O)O</smiles>

Estrutura do ácido succínico

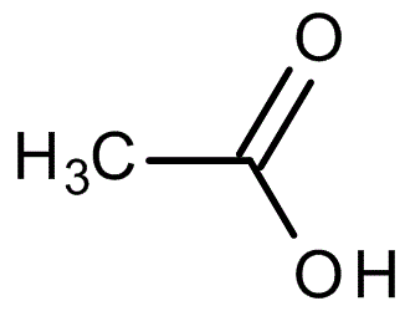

Estrutura química do ácido acético

\section{CONCLUSÃO}

Conclui-se a partir desse estudo que a incorporação do ácido succínico na formação dos filmes de quitosana aumentou a sua capacidade de absorver água aumentando assim o seu ganho de massa, portanto esse reagente é uma nova e interessante alternativa para confecção desses filmes. No entanto não se trata de um estudo definitivo, visto que outras características devem ser analisadas a fim de indicar o melhor processo de produção das mesmas, de acordo com a aplicação de interesse.

\section{NOMECLATURA}

$\Delta \mathrm{m}=$ variação de massa

$\Delta \mathrm{p}=$ variação de pressão

$\%=$ percentagem

$\mathrm{g}=$ gramas

$\mathrm{h}=$ horas

$\mathrm{m}^{2}=$ metro quadrado

$\mathrm{m}^{2} / \mathrm{s}=$ metro quadrado por segundo

$\mathrm{mL}=$ mililitro

$\mathrm{mm}=$ milímetro

$\mathrm{NaCl}=$ cloreto de sódio

$\mathrm{Q} 4 \% \mathrm{Ac}=$ utilizado para nomear os filmes produzidos a partir de quitosana e ácido acético

Q4\%As= utilizado para nomear os filmes produzidos a partir de quitosana, ácido acético e ácido succínico 
$\mathrm{rpm}=$ rotações por minuto

\section{REFERÊNCIAS BIBLIOGRAFICAS}

ASSIS, O. B. G. (2010), Alteração do caráter hidrofílico de filmes de quitosana por tratamento de plasma de HMDS, Química Nova, 33, 3.

COSTA, P., LOBO, J. M. S. Modeling and comparison of dissolution profiles. Eur. J. Pharm. Sci., Amsterdam, v. 13, n. 2, p. 123-133, 2001 b.

DALlAN, P. R. M.; Síntese e caracterização de membranas de quitosana para aplicação na regeneração de pele. Campinas, SP: [s.n.], 2005. Tese (Doutorado) Universidade Estadual de Campinas, Faculdade de Engenharia Química.

LIMA, M. S. P.. Preparo de membranas de quitosana modificadas com poli(ácido acrilico). Dissertação Mestrad Universidade Federal do Rio Grande do Norte. 2006.

RINAUDO, M.; MILAS, M.; DUNG, P. L.; Characterization of chitosan. Influence of ionic strength and degree of acetylation on chai expansaion. International Journal of Biological Macromolecules. v.15, 281-285, 1993.

Taxa de permeabilidade ao vapor d'água- TPVA ASTM E96M-05 (ASTM,2005).

WANG, W.; BO, S.; LI, S.; QIN, W.; Determination of the Mark-Houwink equation for chitosans with different degrees of deacetylation. International Journal of Biological. 1991. 